\title{
LUT
}

University

\section{Inter-organizational Integration in the AEC/FM Industry}

Exploring the "Addressed" and "Unaddressed" Information Exchange Needs Between Stakeholders

\author{
Camposano José Carlos, Smolander Kari
}

This is a Final draft

version of a publication

published by Springer, Cham

in International Conference on Advanced Information Systems Engineering CAiSE 2019:

Advanced Information Systems Engineering

DOI: $10.1007 / 978-3-030-21290-2 \_5$

Copyright of the original publication: () Springer Nature Switzerland AG 2019

Please cite the publication as follows:

Camposano J.C., Smolander K. (2019) Inter-organizational Integration in the AEC/FM Industry. In: Giorgini P., Weber B. (eds) Advanced Information Systems Engineering. CAiSE 2019. Lecture Notes in Computer Science, vol 11483. Springer, Cham

This is a parallel published version of an original publication.

This version can differ from the original published article. 


\title{
Inter-organizational integration in the AEC/FM industry Exploring the "addressed" and "unaddressed" information exchange needs between stakeholders
}

\author{
José Carlos Camposano [0000-0002-7782-5700] and Kari Smolander [0000-0002-7043-0458] \\ LUT School of Engineering Science, LUT University, Lappeenranta, Finland \\ \{jose.camposano, kari.smolander\}@lut.fi
}

\begin{abstract}
This paper explores how the needs to exchange information across organizational boundaries in the Architecture, Engineering and Construction, and Facilities Management industry in Finland have been satisfied by means of stakeholder integration at the technical, business and socio-organizational levels. We interviewed practitioners about their motivations and goals for inter-organizational integration and observed different discourses. The information exchange needs in the context of individual building projects were often described as "addressed". These needs focused mainly on managing complex stakeholder relations or handling the variable conditions with other building projects. In the scope of the whole built environment lifecycle, the needs were rather portrayed as ongoing problems still "unaddressed". Existing information sources remained inadequate when the benefits of inter-organizational integration had not yet been clarified. The process workflow discontinuities demanded better understanding of the value of information beyond design as well as better coordination. The uncertainty of how much data to collect and for what purposes can be mitigated by defining "useful minimum" information exchange between stakeholders.
\end{abstract}

Keywords: inter-organizational integration, information exchange, built environment, building lifecycle management, information systems, AEC/FM.

\section{$1 \quad$ Introduction}

A prominent feature of the Architecture, Engineering and Construction, and Facilities Management industry (AEC/FM) is its complex network of interrelated stakeholders, who are becoming increasingly dependent on the exchange of information across organizational boundaries. This provides an interesting background context to study the systems integration and information management requirements to fulfill both shared and individual tasks. Unlike the manufacturing industry, the stakeholders of the AEC and FM sectors do not operate inside organizational structures with clear boundaries. They rather operate within project-based networks of partner organizations collaborating in a temporary arrangement [17], which do not always interact directly with each other [26]. Besides the reliance on mutual data and information exchange to perform their activities effectively, the work of these various firms is generally framed within 
the same regulatory frameworks and customer demands. In this context, performance and competitiveness are not just within the control of a single organization but rather depend on the efficiency of whole network. Therefore, the technological strategies of these companies must often extend beyond their immediate boundaries, so the technologies they own can be managed effectively [11].

To address these issues, AEC/FM organizations may decide to implement information systems (IS) that integrate across organizational borders. Nam and Tatum [20] already observed more than two decades ago that the integration between design and production functions in AEC projects was linked to increased industry innovation. Since the early 2000s, industry stakeholders have increasingly adopted Building Information Modelling (BIM) solutions to improve their design and construction practices. BIM is generally understood as an overarching term for various object-oriented Computer-Aided Design (CAD) activities, which support the representation of building elements in terms of their 3D geometric and non-geometric (i.e. functional) attributes and relationships [12]. It has been credited for enhanced collaboration and productivity in AEC practices [4, 12].

The aim of this paper is to explore how the information needs of the Finnish AEC/FM industry stakeholders have been satisfied by integrating not only technical solutions such as BIM, but also by adapting at the business and socio-organizational levels. It has been previously argued that IT integration alone is insufficient to overcome the fragmentation of AEC operations and should be thus augmented by other means [20]. Bryde et al. [4] also claim that technical interoperability problems are more likely to be resolved over time by IT companies, but harder issues to solve are to make people agree on common IT platforms or to cooperate with each other. The present study approaches then the integration of IS from a holistic point of view, emphasizing not only the technical dimension of integration and interoperability, but also the business and socio-organizational aspects. From the perspective of AEC/FM practitioners, it can help to understand the implications of inter-organizational integration in the design, construction and operation of buildings. From the perspective of software engineers, it can also serve as a tool to design and develop more effective IT solutions that address the current problems faced by the industry.

During the course of this study, interviewees adopted different discourses when approaching the subject of integration across organizational boundaries. In the context of "building projects", informational needs were usually described as if they had been covered already by a combination of technologies, work processes or business models. At the same time, when the scope was broadened to the more abstract concept of "built environment lifecycle", participants rather provided descriptions of persistent ongoing problems, which they believe could be still mitigated through a more effective information exchange between stakeholders. Based on this discourse characterizing the needs for inter-organizational integration as surmounted or pending, this paper aims to answer the questions "How have the stakeholders of the Finnish AEC/FM industry addressed their information exchange needs so far?" and "Which information exchange needs have yet to be addressed and why?".

The paper is structured as follows: Section 2 introduces the concepts of the built environment lifecycle and inter-organizational integration, which are essential for the 
study subject. Section 3 describes the research process, situating the reader within the case study context and providing a detailed account of the steps taken by the authors. Section 4 presents the most relevant findings grounded on the collected interview data without a priori hypotheses from academic literature. Section 5 discusses these findings in the context of previous studies. The paper ends by clarifying the research limitations, providing future research suggestions and recapping its main conclusions.

\section{Background}

\subsection{The built environment lifecycle}

The AEC industry has been characterized as a loosely coupled system [8] or as a project-based productive network [11], utilizing separate firms with diverse technical capabilities in a temporary multidisciplinary arrangement to produce investment goods like buildings, roads or bridges according to unique specifications [17]. Construction projects can be considered within the scope of the broader field of studies known as the "built environment", a multidisciplinary concept comprising diverse aspects of urban design, land use and human activity within their physical environment [14].

The lifecycle of a building can be broadly articulated into two parts divided by the point in time when its construction has been completed. The first part refers to the planning, design and assembly activities in architecture, engineering and construction (AEC) projects, while the second part refers to the exploitation of the "completed" building which entails different facility management (FM) tasks. The teams that participate on either one of these parts rarely take part also in the other [26]. Throughout this paper, the first part will be referred to simply as "building project" or "construction project". On the other hand, the concept of "built environment lifecycle" will be used as a reference to all stages before, during (i.e. first part) and after (i.e. second part) the building project takes place.

Table 1. Identified stakeholders of the Finnish AEC/FM industry

\begin{tabular}{ll}
\hline Stakeholder & Group (Based on Gann and Salter [11]) \\
\hline State government agencies, local authorities & Regulatory and institutional framework \\
$\begin{array}{l}\text { Designers (architects) and engineers (struc- } \\
\text { tural, HVAC, electrical, plumbing) }\end{array}$ & Project-based firms \\
Main contractors (construction companies) & Project-based firms \\
Sub-contractors (site workers, consultants) & Project-based firms \\
Professional associations & Technical support infrastructure \\
Universities and research institutes & Technical support infrastructure \\
Trade unions & Supply network \\
BIM or FM software providers & Supply network \\
Property owners, landlords & Projects \\
Facility managers, maintenance companies & Projects \\
Tenants & Projects \\
\hline
\end{tabular}

The analysis of relevant industry documentation and the primary data collected from interviews allowed the authors of this study to identify some key stakeholders of the 
AEC/FM industry in Finland, which are listed in Table 1. These have been mapped to each one of the groups described in the model of innovation and knowledge flows in construction industries by Gann and Salter [11].

\subsection{Inter-organizational integration}

Previous scientific literature has approached integration issues in different ways according to the primary aim or focus of the study [2]. The disciplines studying systems of human endeavor, such as IS, management or software engineering, have widely discussed this topic under interchangeable terms such as "organizational integration" [2] or "enterprise integration" [5]. In this context, integration can be defined as "the extent to which distinct and interdependent organizational components constitute a unified whole" [2], where the term "component" refers to organizational units, departments or business partners, and includes in either case the business processes, people and technology involved [2, 21].

IS, management and software engineering scholars have also proposed different classifications of integration, which are often used to explain two intertwined but rather distinct aspects: "what" is to be integrated and "at what scope" is the integration occurring. In the case of "what", Molina et al. [19], Vernadat [27] and Chen et al. [5] described three forms of integration: Physical systems, application and business/knowledge, which aim to support the organizational needs for communication, cooperation and coordination/collaboration, respectively. As an example of "at what scope”, Barki and Pinssoneault [2] used the process chain of the organizations as an overarching concept to classify integration into internal (i.e. intra-organizational) and external (i.e. inter-organizational), with further subcategories each. This study adopts the classification by Kähkönen [16], who considers holistically both the "what" and "at what scope" by approaching integration from three perspectives that build on top of each other: Technical, business and socio-organizational. Throughout this paper, we refer to these categories interchangeably as levels or layers of integration. The present study approaches thus the concept of inter-organizational integration as the collaborative work of industry stakeholders using a combination of technical, business or socioorganizational methods. The following sections will describe some of the information exchange needs (or simply information needs) that can motivate such phenomena.

\section{$3 \quad$ Research process}

This paper presents observations from a qualitative case study, taking the whole of the AEC/FM industry in Finland as unit of analysis. Case studies aim to provide in-depth understanding of a case or a set of cases. The unit of analysis is generally bound in time and place to a concrete entity within a real-life context, such as an individual or an organization, but at a more abstract level it can also refer to communities, relationships, programs, decisions, implementation projects or organizational changes [7, 29]. The findings of this study are grounded on data from semi-structured interviews conducted during the first half of 2018 with 24 stakeholders of AEC/FM industry in Finland, 
namely practitioners from private organizations in directive, managerial or project management roles, as well as public sector officers assigned to strategic projects. The participants represent altogether every stakeholder group from the model of innovation and knowledge flows in construction industries by Gann and Salter [11].

Semi-structured interviews combining specific and open-ended questions were selected as the primary data collection method, because they allowed to maintain consistency between interviews and keep focus on the relevant study topics, while providing also the opportunity to get unexpected insights into the participants' experiences [23]. Topics were covered without a predetermined order to allow for a more natural conversation [6]. Additionally, practitioners had the opportunity at the end of the interview to add anything else they considered important for the topic. To reduce potential biases in the questions and to confirm their relevance [9], the questionnaire ${ }^{1}$ was pilottested with different researchers than the one who conducted the interviews.

Case studies employ purposive or theoretical sampling rather than random sampling, by selecting the cases which are most relevant to the study proposition $[9,10]$ and which are likely to replicate or extend the emergent theory. The network of participants in this study had been involved in key projects of the Finnish government to promote the digitalization of the local AEC/FM industry and were selected because they were likely to be more interested and informed about the topic of this study. The initial interviewees were the "gatekeepers" or main contacts in each organization. Each practitioner was asked to suggest names of other key people to interview later. This process was repeated until additional interviews did not provide any new relevant findings or contributions [22] or more specifically, when the concepts emerging from the data could not be developed further in terms of their properties or dimensional variation [6]. To decide whether this point of "saturation" had been reached, a discriminant sampling strategy [7] was applied, verifying if any codes and categories derived from early interviews held true to explain the answers provided by the subsequent participants as well. Table 2 shows a list of the study interviewees, along with the identifiers used in their quotes throughout this paper. Their names have been removed to preserve anonymity.

All interview sessions lasted between 45 and 90 minutes and were performed with a single participant, except for two interviews in which two participants were present in the room at the same time. The audio of the interviews was recorded for later transcription, coding and analysis using the Atlas.ti tool. Coding was done without a priori hypotheses in mind, so the categories could emerge directly from the data itself. This process was conducted first for each interview transcript and then across interviews, by comparing the similarities and differences in the participants' answers, adhering to the guidelines by Eisenhardt [10] of within-case data analysis followed by a cross-case search of patterns. Codes with a higher level of abstraction, or categories, were also derived from the constant comparison of the researcher's notes and memos.

Besides the interviews, secondary data sources such as news articles and reports were employed to gain better understanding about the technical concepts and terminology of the AEC/FM disciplines, identify potential interviewees and place the answers of the study participants into the current context of the local industry.

${ }^{1}$ The interview guide can be accessed through this link: https://doi.org/10.5281/zenodo.2577038 
Table 2. Study interview participants (*, ** = Interviewed simultaneously)

\begin{tabular}{lll}
\hline Interviewee ID & Organization & Role \\
\hline n1 & A: Construction contractor & Chief Information Officer \\
n2 & A: Construction contractor & Development Manager \\
n3* & B: BIM software provider & Business Director \\
n4* & B: BIM software provider & Product Manager \\
n5** & C: BIM software provider & Product Development Director \\
n6** & C: BIM software provider & Customer Success Manager \\
n7 & D: Property owners association & Project Manager \\
n8 & E: Technology consultancy services & Senior Enterprise Architect \\
n9 & F: Public-private partnership & Chief Digital Officer \\
n10 & F: Public-private partnership & Project Assistant \\
n11 & G: Trade union partnership & Development Manager \\
n12 & H: Public sector, real estate & Senior Expert \\
n13 & I: Public sector, State government & Senior Specialist \\
n14 & J: FM software provider & Technology Director \\
n15 & K: Universities and research institutes & BIM Professor, Architect \\
n16 & L: Public sector, State government & R\&D Specialist \\
n17 & M: Public sector, local authorities & Special Planner \\
n18 & N: Construction consultancy services & Partner and Senior Advisor \\
n19 & O: Construction contractor & Chief Technology Officer \\
n20 & O: Construction contractor & Development Manager \\
n21 & P: Trade union & Managing Director \\
n22 & Q: Engineering sub-contractor & Research Project Manager \\
n23 & R: Public sector, State government & Senior Adviser \\
n24 & S: Construction consultancy services & Project Manager \\
\hline
\end{tabular}

\section{$4 \quad$ Findings}

During the interviews, study participants had the opportunity to reflect upon and describe information exchange needs which demanded some form of inter-organizational integration at the technical, business or socio-organizational level. Rather than elaborating an exhaustive list of information requirements and integration methods for the $\mathrm{AEC} / \mathrm{FM}$ industry stakeholders, this section focuses on the most relevant ones recognized by the interviewees. Based on the analysis, coding and categorization of their answers, the main findings have been summarized in Table 3 .

The different narratives given by the study participants were carefully analyzed. When the questions and answers were constrained to the complexity within a single construction project or the variability between many of them, stakeholder information needs were often described as surmounted. At the same time, when the interview discussion was framed in the broader and more abstract concept of the built environment lifecycle (i.e. including phases before and after the building project) the integration needs - particularly those related to how the information is stored, managed or exchanged between stakeholders - were rather equated to ongoing issues yet to be solved. 
The different discourses can be observed in the following interview excerpts in the scope of building projects and the built environment lifecycle, respectively:

- n1: "In one of our big sites this is already functioning [...] when (our suppliers) deliver the slabs, the elements to the site [...] their logistics system (tells) our system when it is delivered and installed, and all that is visualized in this model. They integrate to our systems, so we know exactly where they are. And that is also good for them, because they know what is the status where we are in this particular project right now."

- n19: "We want to digitalize first the construction phase, so we can get the information flowing to the maintenance phase. It is like bridge building: Digitalize the site and automate the data collection [...] then the next step is to discuss with those who are maintaining the building. They have their own needs [...] it is very difficult to convert the data, even if it exists, but it is not available for their needs. So we have to somehow digitalize the construction phase first and then we will be ready to move on with the lifecycle."

These two discourses may not necessarily reflect the current maturity stage of interorganizational integration within the individual organizations or the industry overall, but rather provide an indication that stakeholders are more or less certain on "what" has been integrated so far - or still needs to be integrated - when the dimension of " $a t$ what scope" changes. For this reason, the categories of "addressed" and "unaddressed" are presented between quotation marks ("') throughout this paper.

Table 3. Information needs and integration methods recognized by interviewees

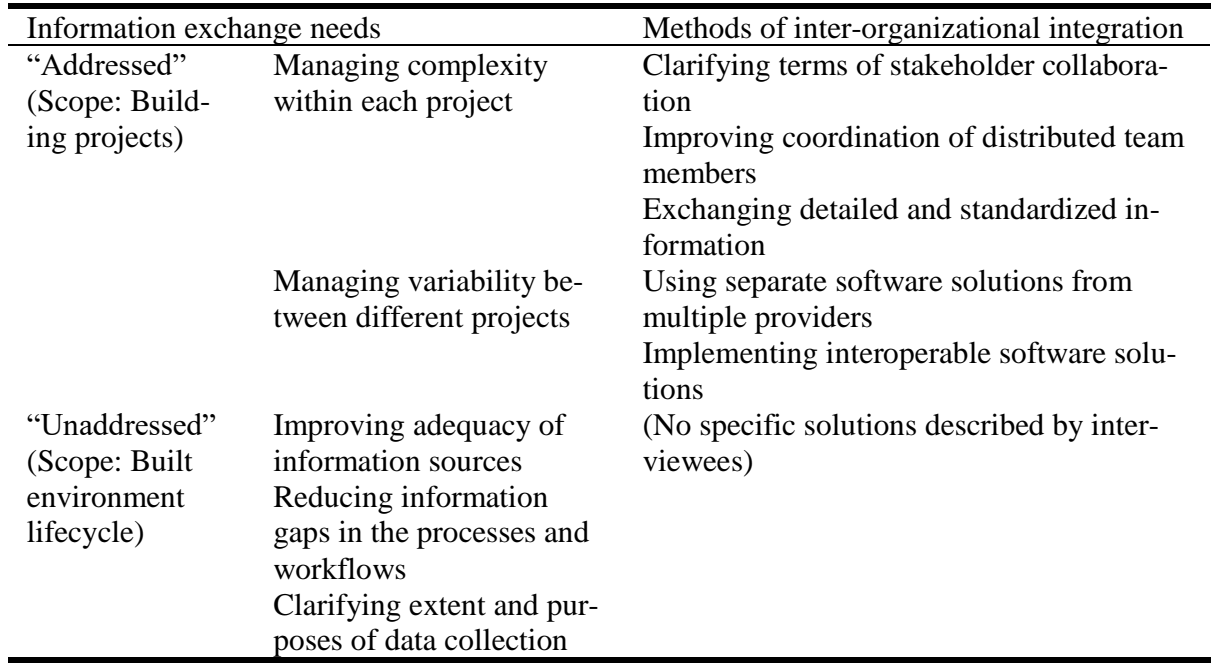

\subsection{Recognized and "addressed" information needs}

Practitioners were prone to describe the information needs related to building projects as relatively covered by various technological or business methods of inter-organizational integration. Two categories were observed in this scope of discussion: The needs 
to manage the complex stakeholder relations within each single project and the needs to handle the variability between multiple projects.

Managing complexity within each project. When looking at each building project, the inter-organizational integration solutions described by interviewees were mainly focused on handling the large number of parts involved, one of the complexity factors influencing the managerial objectives in the industry [13].

- Clarifying terms of stakeholder collaboration: Interviewees often stated that "alliance model" contracts (i.e. various companies participating as consortium in a project) have become a common practice and an incentive for integrating with other stakeholders, as they could evidence the business value of their collaboration.

- Improving coordination of distributed team members: Interviewees also expressed that inter-organizational integration helped resolve clashes during the design and construction stages of the building project, occurring because of the split teamwork, or to track the changes occurring at the construction site. Practitioners have adopted different software tools for collaboration and communication on a per-project basis but gathering the decision-making representatives into the same physical space or "big room" was considered a more effective way to resolve any emerging conflicts.

- Exchanging detailed and standardized information: The increasing use of BIM tools has allowed the project-based firms to improve the technical quality of their designs, by specifying with greater level of detail the object information in domain-specific (e.g. structural, architectural, electrical, etc.) or combined models. BIM standardization and portability through .IFC format files was deemed by interviewees as a factor that facilitates the coordination between the parties involved in construction projects.

Managing variability between different projects. When interviewees looked across multiple building projects, information needs were rather aimed at working in different contexts, for instance due to the size and expertise of the companies involved. Discussions centered thus on how flexible the current software solutions were to allow such adaptation. Practitioners across all stakeholder groups and particularly main contractors expressed their lack of preference towards large applications developed by a single vendor, showing more interest on testing different kinds of software tools or adopting more interoperable solutions that could be easily combined. Rigid software products with many features were often labelled as too restrictive or belonging in the past, whereas the new kinds of software products that stakeholders aim for were frequently described using high-level terms such as "open", "integrated" or "platform".

The motivations of the interviewees from project-based firms (e.g. software users within AEC contractors) differed from those of the "supply network" stakeholders group (e.g. BIM software providers). The first ones indicated they were willing to test and use different software tools or applications depending on the project conditions, without committing to any particular software vendor. Some of the factors taken into account were the size of the other companies involved in the project, or the different levels of technical expertise of the sub-contracted staff. 
- n1: "We optimize always those tools we are using, bringing in new ones and taking out old ones [...] It is actually up to the project to decide which tools and systems to use."

- n2: "Partnering [with the software providers] might be still a strong word. We are partnering in the sense that we are testing different companies' platforms."

The contractors' predisposition to switch easily between different software products has not gone unnoticed by the application vendors. From their perspective, it has become imperative to deliver more value for the users based on the existing technical resources they already provide. Interviewed software providers pointed out that such customer value may not come only from the features inherent to the offered products or services, but also from the flexibility given to the users to adapt, combine and maintain by themselves the applications from different vendors. Partnering was seen as a convenient alternative to avoid developing integrated software solutions from scratch, by combining instead the technical capabilities and expertise of different companies.

— n5: "We have not discussed [with our customers] if they are building their own software [...] if we can provide good solutions for our customers, even though they are using some different applications, then I think they will pay for our platform as well."

- n14: "We [different vendors] are giving three software [tools] that clients see as one [...] we are not dealing with gigantic systems which are closed, that's the dinosaur thinking."

\subsection{Recognized but "unaddressed" information needs}

When interviewees discussed about information needs in the scope of the entire built environment lifecycle, they were less confident that their organizations were suitably integrated. The adequacy of the existing information sources, the process and workflow discontinuities, and the uncertainty of how much data to collect and for what purposes were three topics generally described as problems that still have to be solved.

Improving adequacy of information sources. The prevalence of inadequate sources of building information was a concerning issue for most stakeholder groups, but appeared particularly pressing for the FM organizations, who must manage buildings that may have not been designed and constructed using modern software tools. These concerns referred to information from either analogue (i.e. paper-based) or digital sources. In the first case, interviewees mentioned that industry stakeholders still rely on paperbased designs, blueprints or models which are outdated or inconsistent. In terms of information already available in digital format, legacy IT systems, data silos and unnecessary replication were deemed as recurrent integration problems.

— n3: "There is one large construction company with a 300-point solution developed by themselves [...] they use it to solve a certain issue or task, but they recreate [every time] the whole information, which would be available if they looked at the bigger picture."

- n6: "When you import and export data from our database, it means that you will lack some information [...] we have customers who are exporting an XLS file [using] another software, so you get only like five columns of data." 
Reducing information gaps in processes and workflows. Interviewees frequently commented about a critical breaking point in the flows of information between the AEC and FM phases of the built environment lifecycle. Their examples highlighted the improbability of the use/operation/maintenance stakeholders (e.g. FM staff, building inhabitants) to know in advance specific data to maintain the building, such as manufacturer name and model of the supplies they require. Interviewees in the FM segment claimed that most of the relevant information they needed was lost between AEC and FM, whereas unnecessary information is also transferred between the parties. Most practitioners attributed these information "continuity" problems to the temporary involvement of people rather than to the project scale. They suggested a leadership or coordination role was needed to oversee the information flows across the entire built environment lifecycle, as every stakeholder had just a limited view of the building data.

- n19: "Who can provide the 'as-built' model to the one [that] maintains the building? Basically what you get is the BIM model, which is 'as-designed' model, then you have lots of information in different documents where you describe what happened and that's it."

- n2: "You have different parties involved in different stages, but you don't have this leadership role [...] you don't have someone who looks at the whole lifecycle, which means there is a lot of data gaps and discontinuities."

Interviewees across different stakeholder groups believe BIM may become a solution to improve such process workflows, because the data contained in the models can be used for other purposes besides designing with high precision and improved quality. BIM was also seen as a method to reduce manual work and repetitive tasks, by automating the information exchange between stakeholders. Thus, study participants frequently interpreted the acronym BIM as "Building Information Management".

Uncertain extent and purposes of data collection. Research participants often expressed they already had the technical resources to collect and store vast amounts of information about the buildings. At the same time, interviewees also stated it was difficult to determine which data were valuable or could be shared between stakeholders, as in most cases the usage scenarios and benefits to the organization, its partners or customers were yet to be determined.

- n21: "We want this information to be given through the whole supply chain to the final customers [...] it is too much information that in different systems it's difficult to use."

- n24: "We have a project with the FM team about how they can use our data of design and construction [...] but FM doesn't need all that [...] there is so much information."

Interviewees gave multiple examples of use cases where it was not so important to collect more data but rather just the right pieces of data according to the user and purpose. This notion has been discussed among practitioners as the "useful minimum". 


\section{Discussion}

A frequent aspect observed across all "addressed" information needs is how clearly the interviewees could articulate the resulting value of inter-organizational integration. From the perspective of the project-based firms, the flexibility to cope with variable conditions between multiple construction projects or dealing with many parties involved on each individual project are important motivations to integrate. Supply network stakeholders pursue rather better products and services built from existing technical resources. For interviewees of other stakeholder groups, the improved decisionmaking based on the lifecycle information can be considered an important incentive. Therefore, it can be argued that practitioners across all stakeholder groups aim at efficiency gains through inter-organizational integration.

Another element observed on both the "addressed" and "unaddressed" needs is the difficulty to make a clear distinction between levels of integration (i.e. technical, business and socio-organizational), because all of them are closely intertwined as Kähkönen [16] argues. Even the interoperability and compatibility between software products, which can be considered just a technical matter, is strongly associated to the business goals of both providers and end users. On one hand, contractors are willing to pay for interoperable solutions to minimize workload or automatize manual repetitive tasks. On the other hand, software vendors are keen on providing open APIs and develop partnerships with other companies to improve the value of their products in a way that could not be achieved otherwise. Thus, incorporating the features from potential competitors becomes a cost-effective alternative to avoid being replaced by them. In summary, the integration of software across organizational boundaries is perceived not so much as an incentive on its own right, but as the means to achieve higher-level business goals. This may also explain why the "addressed" information exchange needs have been often solved by establishing partnerships between AEC/FM stakeholders, ensuring that both the technical and business incentives are clear for the parties involved.

Table 4. "Unaddressed" information exchange needs and their possible reasons

\begin{tabular}{ll}
\hline "Unaddressed" information exchange needs & Possible reason(s) \\
\hline Improving adequacy of information sources & $\begin{array}{l}\text { Shared value of inter-organizational integra- } \\
\text { tion not clearly agreed upon }\end{array}$ \\
$\begin{array}{l}\text { Reducing information gaps in processes } \\
\text { and workflows }\end{array}$ & $\begin{array}{l}\text { Value of utilizing BIM beyond design not } \\
\text { Lully understood }\end{array}$ \\
$\begin{array}{l}\text { Llarifying extent and purposes of data col- } \\
\text { organizational integration }\end{array}$ & $\begin{array}{l}\text { "Useful minimum" information exchange be- } \\
\text { tween stakeholders not yet identified }\end{array}$ \\
\hline
\end{tabular}

The remainder of this section will focus on the "unaddressed" information exchange needs summarized in Table 4, which appeared more often when interviewees had to reflect about integrating with other organizations of the whole built environment lifecycle (i.e. beyond construction projects). Understanding these issues and potential solutions can set the course of action for a better integration of the AEC/FM industry. 


\subsection{Improving adequacy of information sources}

Previous studies have noted that incomplete, obsolete or fragmented building information predominates in the industry, resulting in ineffective project management, time loss or cost increases in maintenance, retrofit or remediation processes [28]. According to Shen et al. [24, 25], incorporating legacy systems and achieving higher interoperability is an ongoing challenge of the construction industry. However, technical integration is not a standalone matter that can be analyzed in isolation from other layers of inter-organizational integration. The data silos mentioned by interviewees at technical level went hand in hand with key information gaps at the business level. Companies must invest time and money to develop interoperable solutions, an effort which may not translate into immediate economic benefits. Therefore, it may be necessary to study further how the shared value of inter-organizational integration projects, namely the benefits for every stakeholder, is agreed and communicated.

\subsection{Reducing information gaps in processes and workflows}

The "information breakpoint" between the construction and operation phases of the built environment lifecycle (i.e. between the AEC and FM of AEC/FM) has been already discussed in previous research $[25,26]$. Information about the use of buildings can provide valuable feedback for project-based firms such as contractors. Future research should therefore focus on different use cases of building operation data collection and analysis aimed at providing more value back to the AEC stakeholders, for instance to improve their construction practices or help with the staff training.

Scholars have also acknowledged that applications primarily used to model and visualize building structures can serve other purposes besides design, for instance to facilitate shared understanding across the interdisciplinary groups participating in a building project [3]. The value of BIM beyond the scope of design activities has been covered in previous research $[1,12]$ and more recently, the interest has shifted toward the potential uses of BIM in FM processes such as maintenance and refurbishment [28], or to mitigate the sub-optimal management of information across the entire built environment lifecycle $[4,12,28]$. Researchers are currently studying how the principles of Product Lifecycle Management (PLM) from the manufacturing sector can be adopted by the AEC/FM industry, developing an emerging concept of "Building Lifecycle Management" (BLM) which emphasizes the need for a collaborative management of information throughout the entire building lifecycle, supported by existing and improved BIM solutions [18]. Further studies are needed to assess whether and to what extent these promised BIM benefits have been achieved with existing software solutions.

Another aspect observed in terms of reducing workflow gaps was the lack of a leading entity that can assume the coordination of inter-organizational information exchanges. Dubois and Gadde [8] have examined the different coupling patterns used in AEC projects to coordinate within supply chains, among firms and within firms. Future research could extend such approach to the whole built environment lifecycle. 


\subsection{Clarifying extent and purposes of data collection}

The notion of "useful minimum" has been introduced in the scope of interoperability between software applications implementing IFC exchanges [15]. It emphasizes the need of passing only the most essential information to other stakeholders of the AEC/FM industry. These interdependencies should be understood and mapped at two levels: First among the actors collaborating within each phase of the built environment life-cycle and then between the actors taking over the building tasks in the consecutive phases (e.g. contractor handling out the HVAC/electrical product specifications to FM). These "useful minimum" pieces of information can be also seen as inter-organizational integration requirements and can help stakeholders understand how to keep the essential building data "flowing", particularly addressing the "unaddressed" integration needs outside the scope of building projects, as shown in Fig. 1.

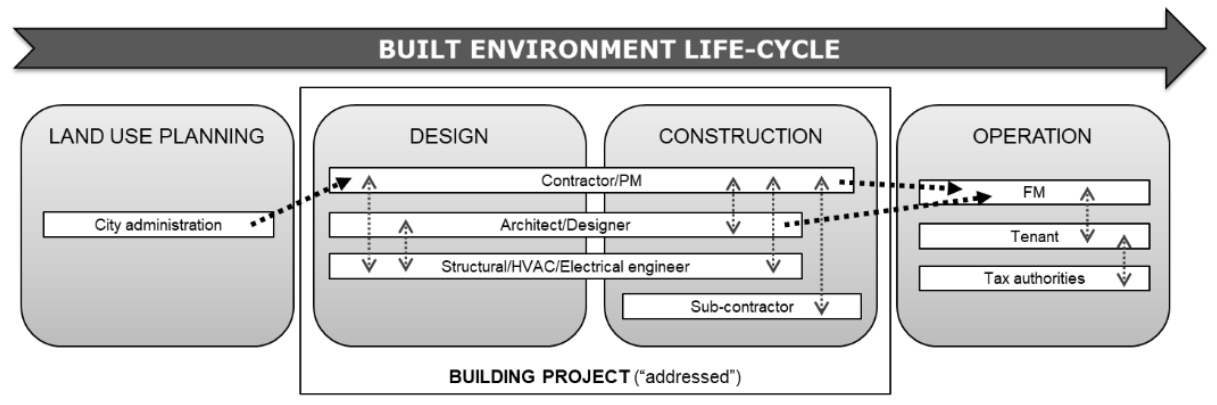

Fig. 1. "Useful minimum" information dependencies integrate stakeholders participating in the same stage (thin arrows) and in different stages (thick arrows) of the built environment lifecycle. Building projects denote boundaries between "addressed" and "unaddressed" integrations.

\section{$6 \quad$ Limitations and future work}

This paper has some limitations regarding data collection, coding and categorization, as these activities were mostly performed by a single researcher. The analysis could be thus enhanced with the inclusion of other researchers bringing different interpretations to the data. Another important limitation was the lack of Finnish-English translation of key industry reports and documents, requiring the occasional involvement of external assistant researchers. Our findings could be further complemented with additional data collection instruments such as surveys, in which the various needs for inter-organizational integration can be assessed or validated with different stakeholders.

This research does not analyze whether and to what extent the "useful minimum" can be attained with different types of IT solutions available during the building lifecycle. Therefore, future studies may benefit from including other research methods relying not only on the opinions of practitioners but also looking at the technical artefacts they refer to, i.e. their BIM tools and software platforms. 


\section{Conclusions}

We explored how the information exchange needs in the Finnish AEC/FM industry have been covered by technical, business and socio-organizational integration methods. When the analysis was limited to building projects, practitioners often described their information needs as "addressed". In such cases, the value of inter-organizational integration was clear, as the involved parties aimed at managing the complex stakeholder relations or handling the variability between different projects. On the other hand, when the discussions about integration were framed in the scope of the whole built environment lifecycle, information needs were presented as "unaddressed" problems: Existing information sources may remain inadequate as long as the shared value of inter-organizational integration is not clearly agreed upon. Process and workflow discontinuities demand a better understanding of the value of BIM beyond design applications, as well as some leadership or coordination. The uncertainty of how much data to collect and for what purposes can be mitigated by establishing "useful minimum" information exchange between stakeholders. This study provides a basis for further IS engineering research focused on how to identify or manage such "useful minimum" dependencies that enable the inter-organizational integration in AEC/FM industry and other sectors.

Acknowledgements. The first author thanks the Department of Computer Science at Aalto University for the office facilities and technical resources to conduct this study.

\section{References}

1. Azhar, S.: Building Information Modeling (BIM): Trends, Benefits, Risks, and Challenges for the AEC Industry. Leadership and Management in Engineering. 11, 3, 241-252 (2011). https://doi.org/10.1061/(ASCE)LM.1943-5630.0000127.

2. Barki, H., Pinsonneault, A.: A Model of Organizational Integration, Implementation Effort, and Performance. Organization Science. 16, 2, 165-179 (2005). https://doi.org/10.1287/orsc.1050.0118.

3. Bouchlaghem, D. et al.: Visualisation in architecture, engineering and construction (AEC). Automation in Construction. 14, 3, 287-295 (2005). https://doi.org/10.1016/j.autcon.2004.08.012.

4. Bryde, D. et al.: The project benefits of Building Information Modelling (BIM). International Journal of Project Management. 31, 7, 971-980 (2013). https://doi.org/10.1016/j.ijproman.2012.12.001.

5. Chen, D. et al.: Architectures for enterprise integration and interoperability: Past, present and future. Computers in Industry. 59, 7, 647-659 (2008). https://doi.org/10.1016/j.compind.2007.12.016.

6. Corbin, J.M., Strauss, A.L.: Basics of qualitative research: techniques and procedures for developing grounded theory. SAGE, Los Angeles (2015).

7. Creswell, J.W., Poth, C.N.: Qualitative inquiry \& research design: choosing among five approaches. SAGE, Los Angeles (2018). 
8. Dubois, A., Gadde, L.-E.: The construction industry as a loosely coupled system: implications for productivity and innovation. Construction Management and Economics. 20, 7, 621-631 (2002). https://doi.org/10.1080/01446190210163543.

9. Easterbrook, S. et al.: Selecting Empirical Methods for Software Engineering Research. In: Shull, F. et al. (eds.) Guide to Advanced Empirical Software Engineering. pp. 285-311 Springer London, London (2008). https://doi.org/10.1007/978-1-84800-044-5_11.

10. Eisenhardt, K.M.: Building Theories from Case Study Research. The Academy of Management Review. 14, 4, 532 (1989). https://doi.org/10.2307/258557.

11. Gann, D.M., Salter, A.J.: Innovation in project-based, service-enhanced firms: the construction of complex products and systems. Research Policy. 29, 7-8, 955-972 (2000). https://doi.org/10.1016/S0048-7333(00)00114-1.

12. Ghaffarianhoseini, A. et al.: Building Information Modelling (BIM) uptake: Clear benefits, understanding its implementation, risks and challenges. Renewable and Sustainable Energy Reviews. 75, 1046-1053 (2017).

13. Gidado, K.I.: Project complexity: The focal point of construction production planning. Construction Management and Economics. 14, 3, 213-225 (1996). https://doi.org/10.1080/014461996373476.

14. Handy, S.L. et al.: How the built environment affects physical activity. American Journal of Preventive Medicine. 23, 2, 64-73 (2002). https://doi.org/10.1016/S0749-3797(02)00475-0.

15. Hietanen, J., Lehtinen, S.: The useful minimum. Tampere University of Technology (2006).

16. Kähkönen, T.: Understanding and Managing Enterprise Systems Integration. Lappeenranta University of Technology (2017).

17. Kamara, J.M. et al.: Knowledge management in the architecture, engineering and construction industry. Construction Innovation. 2, 1, 53-67 (2002).

18. Mangialardi, G. et al.: BIM and PLM Associations in Current Literature. In: Ríos, J. et al. (eds.) Product Lifecycle Management and the Industry of the Future. pp. 345-357 Springer International Publishing, Cham (2017). https://doi.org/10.1007/978-3-319-72905-3_31.

19. Molina, A. et al.: Enterprise Integration and Networking: Issues, Trends and Vision. In: Bernus, P. and Fox, M. (eds.) Knowledge Sharing in the Integrated Enterprise. pp. 303-313 Springer-Verlag, New York (2005). https://doi.org/10.1007/0-387-29766-9_25.

20. Nam, C.H., Tatum, C.B.: Noncontractual Methods of Integration on Construction Projects. Journal of Construction Engineering and Management. 118, 2, 385-398 (1992). https://doi.org/10.1061/(ASCE)0733-9364(1992)118:2(385).

21. Oh, L.-B. et al.: Service-Oriented Architecture and Organizational Integration: An Empirical Study of IT-Enabled Sustained Competitive Advantage. ICIS 2007 Proceedings. 18 (2007).

22. Runeson, P., Höst, M.: Guidelines for conducting and reporting case study research in software engineering. Empirical Software Engineering. 14, 2, 131-164 (2009). https://doi.org/10.1007/s10664-008-9102-8.

23. Seaman, C.B.: Qualitative methods in empirical studies of software engineering. IEEE Transactions on Software Engineering. 25, 4, 557-572 (1999). https://doi.org/10.1109/32.799955.

24. Shen, W. et al.: A loosely coupled system integration approach for decision support in facility management and maintenance. Automation in Construction. 25, 41-48 (2012). https://doi.org/10.1016/j.autcon.2012.04.003. 
25. Shen, W. et al.: Systems integration and collaboration in architecture, engineering, construction, and facilities management: A review. Advanced Engineering Informatics. 24, 2, 196207 (2010). https://doi.org/10.1016/j.aei.2009.09.001.

26. Vanlande, R. et al.: IFC and building lifecycle management. Automation in Construction. 18, 1, 70-78 (2008). https://doi.org/10.1016/j.autcon.2008.05.001.

27. Vernadat, F.B.: Enterprise Int 86. Enterprise Integration and Interoperability. In: Springer Handbook of Automation. pp. 1529-1538 (2009).

28. Volk, R. et al.: Building Information Modeling (BIM) for existing buildings — Literature review and future needs. Automation in Construction. 38, 109-127 (2014). https://doi.org/10.1016/j.autcon.2013.10.023.

29. Yin, R.K.: Case study research: design and methods. Sage Publications, Los Angeles, Calif (2009). 